\title{
PERENCANAAN TATA LETAK GUDANG MENGGUNAKAN METODE CLASS-BASED STORAGE- CRAFT PADA DISTRIBUTOR COMPUTER \& OFFICE EQUIPMENT
}

\author{
Hidayat Muhammad Nur ${ }^{1}$, Vadlya Maarif ${ }^{2}$ \\ ${ }^{1}$ Manajemen Informatika, AMIK BSI Purwokerto, ${ }^{2}$ Sistem Informasi, STMIK Nusa Mandiri Jakarta \\ e-mail: ${ }^{1}$ hidayat.hmm@bsi.ac.id, ${ }^{2}$ vadlya.vir@nusamandiri.ac.id
}

\begin{abstract}
Increased competitiveness can be done through warehouse management, especially finished goods inventory. The condition of storage patterns and preparation of items that are randomly and irregularly will result in the accumulation of goods or the mixing of items in one slot rack. So, this condition will result in a longer search time. This study discusses the planning of warehouse layout and preparation of goods using the Class Based Storage method by optimizing the CRAFT (Computerized Relative Allocation of Fasilities Technique) algorithm for manufacturing facilities or services that focus on the process. The study was conducted by examining 9 product items with the aim of knowing the layout of goods in warehouses, to meet the needs of searching goods accurately by looking for the causes of irregular placement and item preparation, then making the layout of goods in finished goods warehouses. So that it has an additional allocation of storage area allowance of $28.6 \%$.
\end{abstract}

Keywords- Layout, Class Based Storage, CRAFT

Abstrak - Peningkatan daya saing dapat dilakukan melalui pengelolaan gudang, khususnya finished goods inventory. Kondisi pola penyimpanan dan penyusunan barang yang dilakukan secara acak dan kurang teratur akan mengakibatkan terjadinya penumpukkan barang ataupun tercampurnya barangbarang di dalam satu slot rack. Sehingga, kondisi tersebut akan mengakibatkan waktu pencarian yang lebih lama. Kajian ini membahas mengenai perencanaan tata letak gudang dan penyusunan barang menggunakan metode Class Based Storage dengan mengoptimasi algoritma CRAFT (Computerized Relative Allocation of Fasilities Technique) untuk fasilitas manufaktur atau layanan yang berfokus pada proses. Penelitian dilakukan dengan meneliti 9 item produk dengan tujuan mengetahui tata letak barang digudang, untuk memenuhi kebutuhan pencarian barang secara akurat dengan mencari penyebab penempatan dan penyusunan barang yang tidak teratur, kemudian membuat tata letak barang di gudang finished goods. Sehingga mempunyai penambahan alokasi allowance area penyimpanan sejumlah $28.6 \%$.

Kata kunci- Tata Letak, Class Based Storage, CRAFT

\section{PENDAHULUAN}

Sebuah perusahaan bidang computer dan office equipment, seperti usaha dagang, jasa dan lain-lain diperlukan gudang untuk menyimpan barang-barang yang dimiliki oleh perusahaan. Dalam mengelola barang membutuhkan sebuah sistem dan informasi agar dapat mempermudah pengelolaan data barang, untuk menunjang pekerjaan yang berlangsung dengan baik dan lancar.

Teknologi dan informasi dalam pengolahan data diantaranya dalam pengolahan data perencanaan tata letak gudang, dengan maksud akan mempermudahkan bentuk aktifitas seperti menghemat ruang dan penempatan barang.

Pengaturan tata letak gudang yang optimal akan berkontribusi terhadap kelacancaran seluruh operasi gudang bahkan suatu perusahaan. Artinya tata letak gudang yang baik dapat menempatkan berbagai fasilitas dan peralatan fisik secara teratur sehingga mendukung pekerjaan berjalan secara produktif (Zhenyuan dkk, 2011).

Kinerja sistem penyimpanan barang bergantung pada beberapa karakteristik internal dan eksternal. Karakteristik internal meliputi: (1) kapasitas penyimpanan; (2) kemudahan akses ke lokasi penyimpanan; (3) kompleksitas struktur internal; dan (4) dan tingkat teknologi informasi. Sedangkan karateristik eksternal seperti jenis produk, jumlah produk, jumlah persediaan untuk disimpan, dan tipe aliran barang masuk dan keluar.

Tantangan inilah yang saat ini sedang dihadapi oleh CV. Global Technology Solution merupakan distributor computer dan office equipment di Purwokerto. Pertumbuhan penduduk akan kebutuhan peralatan kantor yang cukup pesat telah mendorong terjadinya peningkatan permintaan terhadap produkproduk seperti alat presentasi, sound sistem, alat edukasi dan keamanan. Sebagian besar produk tersebut merupakan umumnya yang 
paling dibutuhkan sehingga perusahaan beroperasi berdasarkan pesanan (make-toorder/MTO) dan kanvas. Karena kondisi tersebut, perusahaan menerapkan kegiatan penempatan barang dengan kebijakan randomized storage, yaitu ditempatkan secara acak tanpa aturan tertentu. Hal ini menyebabkan proses peletakkannya di sembarang tempat, sehingga kapasitas yang dimiliki gudang belum dimanfaatkan secara optimal dan menyebabkan terjadinya penurunan kapasitas gudang sebenarnya.

\section{TINJAUAN PUSTAKA}

\section{Definisi Perancangan Tata Letak}

Perancangan tata letak didefinisikan sebagai perancangan tata letak gudang sebagai perencanaan dan integrasi aliran komponen-komponen suatu produk untuk mendapatkan interelasi yang paling efektif dan efisien antar operator, peralatan, dan proses transformasi material dari bagian penerimaan sampai ke bagian pengiriman produk (James M. Apple, Tata Letak Gudang dan Pemindahan Bahan, diterjemahkan oleh Nurhayati Mardiono, ITB, Bandung, 1990). Maka pengertian perancangan tata letak yang dipakai dalam penelitian ini adalah pengaturan konfigurasi stasiun kerja distributor yang disusun berdasarkan interaksi antar departemen yang memenuhi kriteria-kriteria tertentu sehingga interaksi tersebut optimal.

Perencanaan tata letak penempatan barang merupakan suatu persoalan yang penting, karena distributor akan beroperasi dalam jangka waktu yang lama, maka kesalahan di dalam analisis dan perencanaan layout akan menyebabkan kegiatan penjualan berlangsung tidak efektif dan tidak efisien. Perencanaan tata letak merupakan salah satu tahap perencanaan fasilitas yang bertujuan untuk mengembangkan suatu sistem penjualan yang efektif dan efisien sehingga tercapai suatu proses distribusi yang baik. Studi tentang pengaturan tata letak fasilitas selalu berkaitan dengan minimasi total cost. Yang termasuk dalam elemen-elemen cost yaitu conctruction cost, installation cost, material handling cost, production cost, safety cost, in-process storage cost. Disamping itu, perencanaan yang teliti dari layout fasilitas akan memberikan kemudahan-kemudahan saat diperlukannya ekspansi distributor atau kebutuhan supervisi.

\section{Definisi Gudang}

Menurut David E Mulcahy, (Warehouse and Distribution Operation Handbook International Edition, McGraw Hill, New York, 1994) gudang adalah suatu fungsi penyimpanan berbagai macam jenis produk yang memiliki unit penyimpanan dalam jumlah yang besar maupun yang kecil dalam jangka waktu saat produk dihasilkan oleh gudang (penjual) dan saat produk dibutuhkan oleh pelanggan atau stasiun kerja dalam fasilitas produksi. Gudang sebagai tempat yang dibebani tugas untuk menyimpan barang yang akan dipergunakan dalam produksi, sampai barang tersebut diminta sesuai dengan jadwal produksi. Gudang atau strorage pada umumnya akan memiliki fungsi yang cukup penting didalam menjaga kelancaran operasi produksi suatu gudang. Disini ada tiga tujuan utama dari departemen ini yang berkaitan dengan pengadaan barang (Wignjosoebroto,2003), yaitu sebagai berikut:

1. Pengawasan, yaitu dengan sistem administrasi yang terjaga dengan baik untuk mengontrol keluar masuknya material. Tugas ini juga menyangkut keamanan dari material, yaitu jangan sampai hilang.

2. Pemilihan, yaitu aktifitas pemeliharaan agar material yang disimpan di dalam gudang tidak cepat rusak dalam penyimpanan.

3. Penimbunan atau penyimpanan, yaitu agar sewaktu-waktu diperlukan maka material yang dibutuhkan akan tetap tersedia sebelum dan selama proses berlangsung.

\section{Penempatan Barang}

Penempatan barang adalah kegiatan yan berubungan dengan berdasarkan apa suatu barang ditempatkan dalam gudang. Kebijakan penempatan barang ini berdampak pada waktu transportasi yang dibutuhkan dan proses pencarian atau penelusuran barang.

\section{METODE PENELITIAN}

\section{A. Metode Penelitian}

Setiap penelitian harus menggunakan suatu metode tertentu untuk mempermudah pencapaian tujuan yang diharapkan dari penelitian. Dalam kegiatan apapun, metode dan teknik analisis harus selalu ada sebagai satu kesatuan yang keberadaannya tidak dapat dipisah-pisahkan karena metode dan teknik suatu kegiatan penelitian ini, maka penulis menentukan metode tertentu yang disesuaikan dengan masalah dan tujuan yang telah dirumuskan.

Dalam melakukan penelitian ini penulis menggunakan metode penelitian deskriptif kualitatif karena dalam pelaksanaannya meliputi data, analisis dan interpretasi tentang arti dan data yang diperoleh. Penelitian ini disusun sebagai penelitian induktif yakni mencari dan mengumpulkan data yang ada di lapangan dengan tujuan untuk mengetahui faktor-faktor, unsur-unsur bentuk, dan suatu 
sifat dari fenomena di masyarakat. (Nazir, 1998: 51)

Menurut Sugiyono (2008:5) metode penelitian adalah :

"Cara ilmiah untuk mendapatkan data yang valid dengan tujuan dapat ditemukan, dikembangkan, dan dibuktikan, suatu pengetahuan tertentu sehingga pada gilirannya dapat digunakan untuk memahami, memecahkan, dan mengantisipasi masalah ".

Dari pengertian diatas penulis menyimpulkan bahwa metode penelitian merupakan cara yang dilakukan peneliti dalam menganalisis data untuk memberikan solusi terhadap suatu kondisi yang bermasalah. Dan berikut adalah metode yang yang kami gunakan dalam melakukan penelitian perancangan tata letak gudang.

\section{1) Class-based storage}

Yaitu penempatan bahan atau material berdasarkan atas kesamaan suatu jenis bahan atau material kedalam suatu kelompok. Kelompok ini nantinya akan ditempatkan pada suatu lokasi khusus pada gudang. Kesamaan bahan atau material pada suatu kelompok, bisa dalam bentuk kesamaan jenis item atau kesamaan pada suatu daftar pemesanan konsumen.

Kami menggunakan metode ini untuk menempatkan barang dengan jumlah keluar masuk dan kecepatan perpindahannya yang sama ditempatkan diarea yang sama.

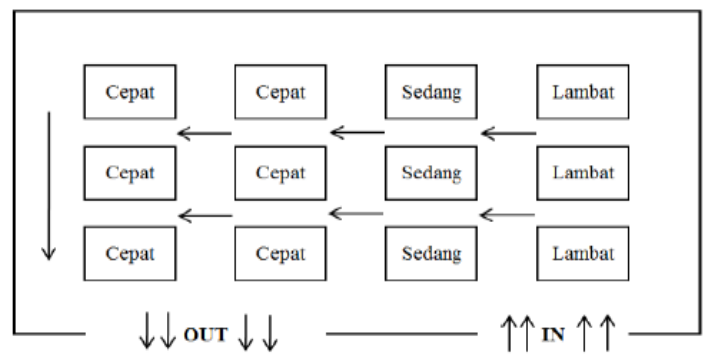

Gambar 1. Contoh penempatan barang menggunakan metode Class-based storage

\section{2) Shared storage}

Penempatan beberapa bahan atau material dalam satu area yang dikhususkan untuk bahan atau material tersebut. Kebijakan ini mengurangi jumlah kebutuhan luas gudang dan mampu peningkatkan utilisasi area penempatan persediaan.

Penggunaan metode ini dengan melihat kapasitas luas bangunan gudang yang digunakan. Sehingga penempatan barang bisa lebih efisien dan efektif. Dengan cara memaksimalkan tinggi dan luas tumpukan barang.

\section{3) Craft}

Adalah algoritma heuristik terkomputerisasi yang mengambil beban matriks arus antar departemen dan biaya transaksi dengan representasi blok tata letak sebagai inputnya. Tata letak blok bisa berupa layout yang ada atau fasilitas baru, tata letak secara random.

Algoritma kemudian menghitung lokasi departemen dan mengembalikan perkiraan biaya interaksi total untuk tata letak awal. Algoritma dirancang untuk menghitung dampak pada ukuran biaya untuk dua arah atau bertukar tiga arah dari lokasi fasilitas. Untuk setiap swap, bermacam-macam biaya interaksi dihitung ulang dan matriks beban dan perubahan biaya (kenaikan atau penurunan) dicatat dan disimpan dalam RAM.

Algoritma ini berjalan melalui semua kemungkinan kombinasi swap, diakomodasi oleh perangkat lunak. Prosedur dasarnya adalah diulang beberapa kali sehingga menghasilkan layout blok yang lebih efisien setiap saat, sampai bila tidak diperlukan pengurangan biaya lebih lanjut. Tata letak blok terakhir kemudian dicetak untuk dijadikan sebagai dasar untuk template tata letak rinci dari fasilitas pada tahap selanjutnya.

\section{B. Objek Dan Lokasi Penelitian}

Objek penelitian ini adalah tata letak gudang CV. Global Technology Solution (distributor computer dan office equipment) penelitian dilaksanakan dimulai pada bulan Mei 2017 sampai dengan saat ini.

\section{Teknik Pengumpulan Data}

Dalam melakukan pengumpulan data, peneliti mendapatkan data bersumber secara langsung (primer) dari perusahaan dan dari yang telah tersedia untuk diproses selanjutnya (sekunder). Data-data yang dikumpulkan antara lain sebagai berikut:

a. Data tata letak gudang

b. Karakteristik karton produk

c. Data jadwal penjualan dan permintaan barang

d. Data aliran barang di gudang

Data-data tersebut dikumpulkan melalui pengamatan peneliti secara langsung dan wawancara dengan pihak terkait.

\section{Tahapan Penelitian}

Adapun Tahapan penelitian ini seperti terlihat pada Gambar 2 dan 3 di bawah ini: 


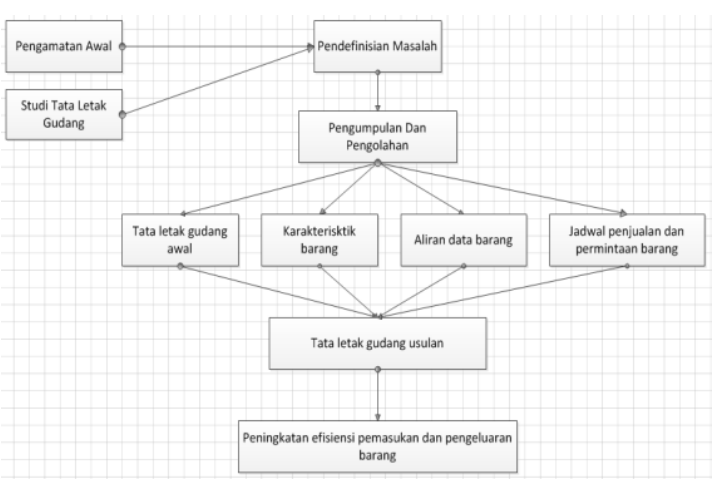

Gambar 2. Model Konseptual

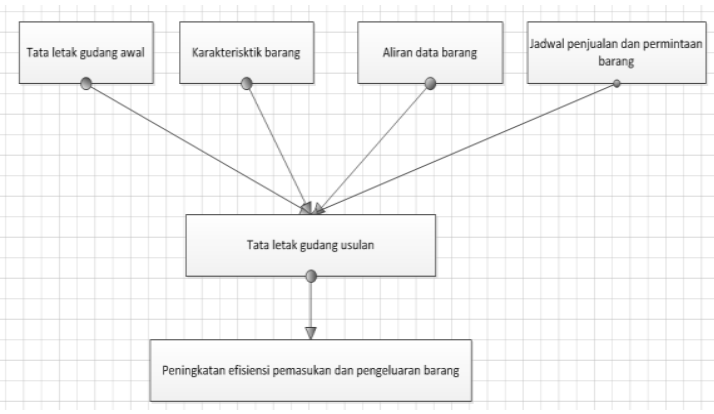

Gambar 3. Tahapan Penelitian

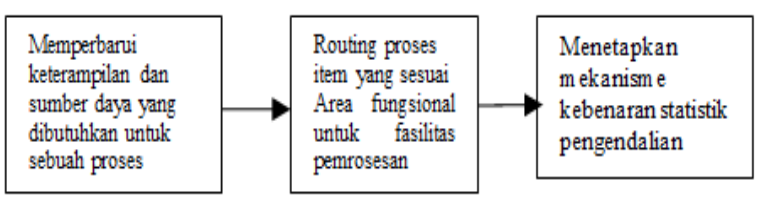

Gambar 4. Perencanaan tata letak rinci

\section{HASIL DAN PEMBAHASAN}

\section{A. Data Hasil Penelitian}

Berikut ini adalah layout gudang saat ini: Ukuran dari gudang distributor adalah $6 \mathrm{mx}$ $10.5 \mathrm{~m} \times 4 \mathrm{~m}$. Proses keluar masuk barang melalui sebuah pintu berukuran $2 \mathrm{~m} \times 2 \mathrm{~m}$ dan pintu masuk keluar operator gudang $2 \mathrm{~m} \times 5$ $\mathrm{m}$. Selain itu, untuk menjamin kelancaran kegiatan pergudangan dalam gudang terdapat beberapa fasilitas. Fasilitas tersebut adalah sebagai berikut:

1) Tempat bongkar muat

Pada tempat ini merupakan lokasi pembongkaran barang dari truk yang dikirim oleh supplier. Dan tempat untuk memasukan barang ke truk pengiriman.

2) Inspeksi

Saat di bongkar dan dimuat barang selanjutnya di inspeksi oleh operator gudang, yang bertujuan untuk mengecek apakah item barang sudah sesuai dengan nota pengiriman atau belum.

\section{3) Penyimpanan barang}

Tempat penyimpanan dibagi menjadi beberapa bagian yaitu barang yang bagus dan barang retur. Lokasi penyimpanan tersebar dengan ketentuan tertentu.

4) Administrasi

Bagian administrasi merupakan bagian yang mengelola administrasi di gudang seperti data keluar dan masuknya karton di gudang. Untuk mendukung kegiatan aliran barang di gudang terdapat beberapa alat material handling. Alat material handling yang digunakan yaitu sebagai berikut:

1) 2 buah Kereta dorong dengan dimensi $1 \mathrm{~m}$ $\times 0.5 \mathrm{~m} \times 80 \mathrm{~cm}$.

2) Operator yaitu semua tenaga kerja yang bekerja digudang. Manusia digunakan jika karton yang dibawa tidak terlalu banyak atau kereta dorong sedang digunakan.

3) Seperangkat komputer berguna untuk membuat mengelola inventory.

\section{B. Pemasukan dan Pengeluaran Barang}

Setiap minggunya barang selalu datang dari supplier dan keluar setiap hari untuk dijual. Pengiriman dari supplier dan pengiriman ke konsumen berlangsung setiap hari dan setiap waktu. Data persediaan barang saat ini dan data keluar dan masuk barang di gudang CV. Global Technology Solution setiap bulan dapat dilihat pada Tabel 1.

Selanjutnya, data pada Tabel 1. akan digunakan untuk penentuan kapasitas gudang saat ini dan digunakan untuk penentuan letak barang karena barang dengan permintaan tertinggi harus diletakkan dekat dengan pintu keluar masuk gudang. Tabel 1, menunjukan jumlah persediaan barang dan data keluar masuk barang. Dari data tersebut dapat terlihat status persediaan barang selama bulan Mei.

Tabel 1. Barang Masuk \& Keluar

\begin{tabular}{|c|c|c|c|r|}
\hline NO. NAMA BARANG & SISA AWAL & M A S U K & K E L U A R & SISA AKHIR \\
\hline \hline 1 PRINTER PRIMATECH PR 88H & - & 6 & 0 & 6 \\
\hline 2 LCD EPSON S400 & - & 30 & 20 & 10 \\
\hline 3 LLCD EPSON X400 & 7 & 20 & 21 & 6 \\
\hline 4 $\mid$ KABEL VGA 15 M & 12 & 80 & 4 & 88 \\
\hline 5 KKABEL RGB 15M & 75 & 0 & 0 & 75 \\
\hline 6 BRAKET BESI F1000 & 16 & 1 & 0 & 17 \\
\hline 7 LAYAR MY SCREEN 70" GANTUNG & 61 & 49 & 0 & 110 \\
\hline 8 LAYAR MY SCREEN TRIPOD 70" & 10 & 5 & 3 & 12 \\
\hline 9 MEIA KURSI IMPARAR O39 STD CENTRO & 9 & 6 & 9 & 6 \\
\hline 10 MEIAA EDU PICOLO & 20 & 27 & 0 & 47 \\
\hline
\end{tabular}

Tabel 1. Persediaan Stock Computer dan Office Equipment CV. Global Technology Solution Bulan Mei 


\section{Barang Masuk}

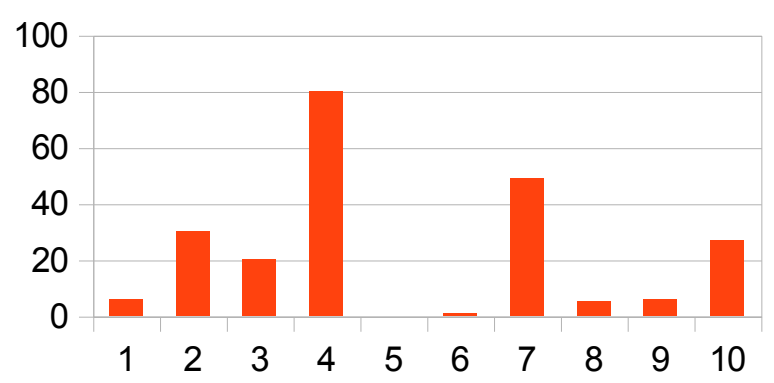

Gambar 5. Statistik Barang Masuk diBulan Mei

\section{Barang Keluar}

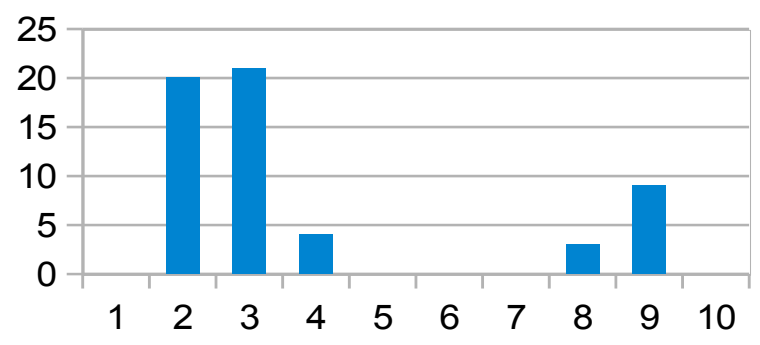

Gambar 6. Statistik Barang Keluar diBulan Mei

\section{Pemindahan barang}

Material dapat dipindahkan secara manual, material dapat dipindahkan disesuaikan dengan kebutuhan. Material dapat dialokasikan pada lokasi yang tetap maupun secara acak atau material dapat ditempatkan pada lantai maupun di atas.

\section{Tata Letak Gudang}

Saat ini barang yang diletakkan di gudang diletakkan secara acak dengan menempati ruang kosong yang tersedia. Sehingga jarak yang ditempuh untuk mengambil barang apapun jenisnya pada kondisi saat ini adalah dari pintu keluar masuk ke seluruh lokasi penyimpanan barang yaitu $5 \mathrm{~m} 2$.

Dalam penentuan kebutuhan ruang digunakan jumlah pembelian, pengembalian, dan sisa awal dari tiap jenis barang. Hal ini dikarenakan barang harus disimpan dalam jumlah yang besar mengingat jarak dari pemesanan dari supplier sampai barang dikirimkan kurang lebih selama 1 minggu. Selanjutnya dari tiap periode dirata-ratakan untuk menentukan kapasitas yang dibutuhkan dalam gudang. Kapasitas yang dibutuhkan diperoleh dengan menghitung jumlah pallet yang harus disimpan.

Total keseluruhan jumlah pallet yang harus disimpan adalah 63 pallet yang terdiri dari barang utama dan barang retur (data selengkapnya terlampir).

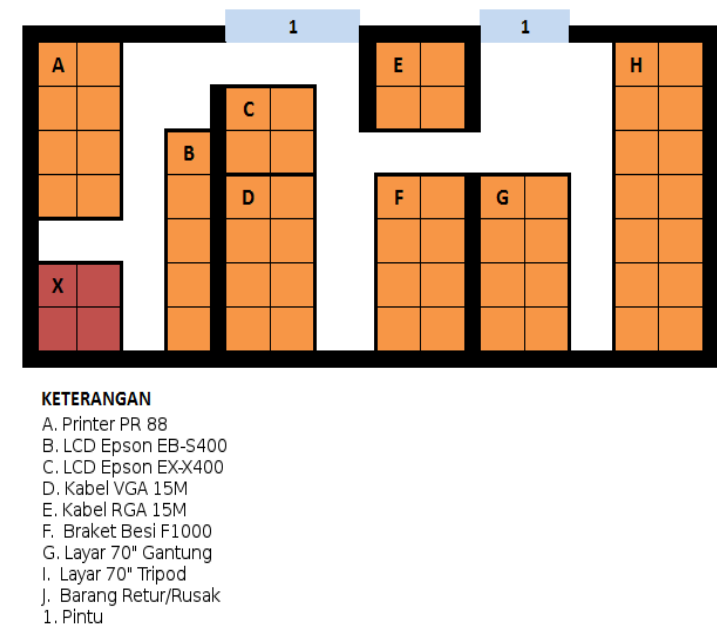

Gambar 7. Tata Letak Gudang

\section{E. Tata Letak Gudang Usulan}

Dalam perancangan tata letak gudang usulan metode penyimpanan yang digunakan adalah class based storage. Metode class based storage akan mengelompokkan barang berdasarkan jenisnya.

Dalam urutan peletakan jenis barang diurutkan berdasarkan rata-rata permintaan dari tiap jenis barang. Jenis barang yang paling tinggi permintannya diletakkan paling dekat dengan pintu keluar masuk. Area pada gudang selanjutnya dibagi menjadi 3 area yaitu area penyimpanan barang, area penyimpanan barang karton rusak/basah, area barang retur.

Setiap area penyimpanan disusun menjadi 9 tumpukan karton per palletnya dengan stapel 11 karton. Kapasitas setiap area penyimpanan diperoleh dengan memperhitungkan dimensi dari pallet dari barang yang diletakkan secara horizontal.

RUMUS = pallet yang digunakan $x$ baris

- Area penyimpanan $A=4 \times 2=8$ pallet

- Area penyimpanan $B=5 \times 1=5$ pallet

- Area penyimpanan $C=2 \times 2=4$ pallet

- Area penyimpanan $D=4 \times 2=8$ pallet

- Area penyimpanan $E=2 \times 2=4$ pallet

- Area penyimpanan $F=4 \times 2=8$ pallet

- Area penyimpanan $\mathrm{G}=4 \times 2=8$ pallet

- Area penyimpanan $\mathrm{H}=7 \times 2=14$ pallet

- Area retur $(X)=2 \times 2=4$ pallet

Gang antar rak diberikan selebar $1 \mathrm{~m}$. Hal ini berdasarkan lebar maksimal dari alat material handling yaitu $0.5 \mathrm{~m}$, karena pada proses penyimpanan sebagian besar menggunakan kereta dorong atau handclift. 


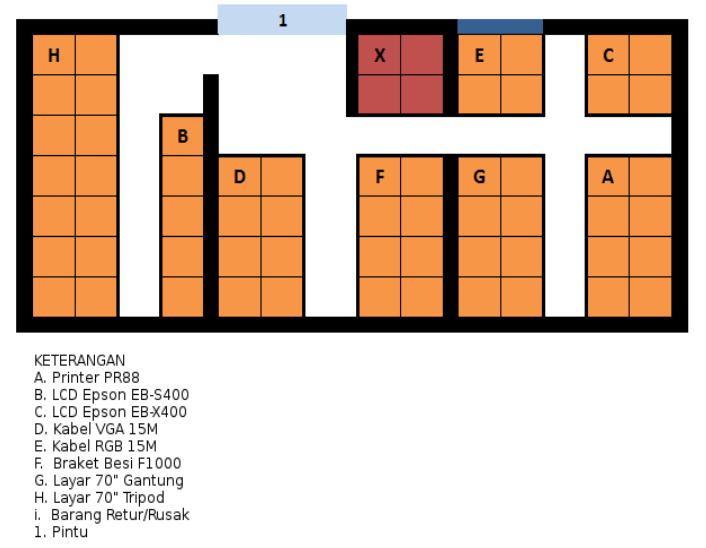

Gambar 8. Tata Letak Gudang Usulan

\section{F. Analisa Pembahasan}

Dalam perancangan tata letak fasilitas dibutuhkan luas lantai yang sesuai untuk proses penyimpanan barang. Kebutuhan ruangan turut memperhatikan allowance yang dibutuhkan oleh tiap fasilitas seperti allowance operator, material, dan material handling. Allowance tersebut tentunya juga membutuhkan sejumlah area untuk menampungnya.

Ketentuan layout yang mengatur bahwa jenis barang yang paling tinggi permintannya harus diletakkan berdekatan dengan pintu keluar masuk mengakibatkan kapasitas penyimpanan gudang meningkat. Total barang harus disimpan adalah 63 pallet dan kapasitas awal gudang untuk menampung karton sebesar 63 pallet.

Guna melengkapi data usulan metode penyimpanan class based storage yang pada dasarnya merupakan gabungan metode dedicated dan randomized storage ini. Penulis mengevaluasi ukuran awal (initial measure) layout gudang saat ini menggunakan algoritma CRAFT dan memanfaatkan menggunakan area vertical. Sehingga operator mendapatkan alternatif pemecahan masalah pada saat mengatasi permintaan barang masuk dengan kapasitas area penyimpanan minimal. Berikut ini adalah tampilan data fasilitas penyimpan gudang setelah dilakukan improving switch menggunakan metode tradisional CRAFT.

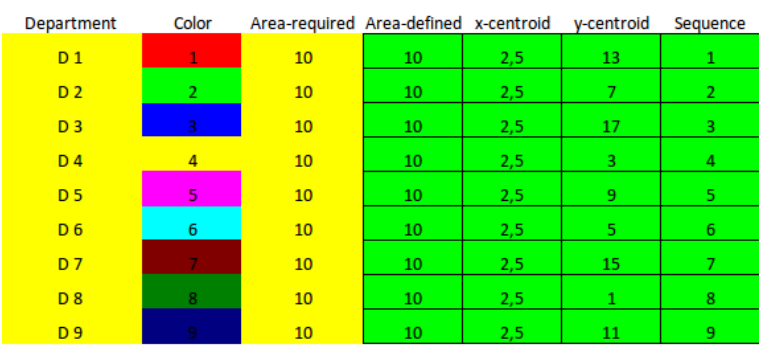

Gambar 9. Alokasi allowance area penyimpanan
Total barang yang dapat disimpan jumlahnya bertambah sejumlah menjadi 81 pallet dan kapasitas awal gudang yang menampung menampung karton sebesar 63 pallet. Ini menunjukkan bahwa solusi awal memang mendekati optimal.

\section{PENUTUP}

\section{A. Kesimpulan}

Gudang diperlukan prosedur yang baik dalam proses penempatan produk, sehingga pemenfaatan handpallet lebih efektif. Setelah dilakukan penyusunan data pada gudang $\mathrm{CV}$. Global Technology Solution Purwokerto maka, dapat diambil beberapa kesimpulan, antar lain:

1. Jumlah kebutuhan area penyimpanan adalah sebanyak 9 area, dengan rincian 8 area untuk pallet penyimpanan barang dan 1 area untuk pallet penyimpanan barang retur. Luas total untuk kebutuhan ruang untuk pallet barang adalah $252 \mathrm{~m}^{3}$.

2. Satu area pallet dilakukan penumpukan 9 tingkat karton dengan stapel, maka setiap pallet terdiri dari 99 karton barang. Lebar gang atau aisle adalah $1 \mathrm{~m}$, sehingga total kebutuhan ruang untuk gang atau aisle adalah sebesar $2.5 \mathrm{~m}^{2}$.

3. Dibutuhkan mekanisme proses memanfaatkan area vertical menggunakan algoritma CRAFT guna memiliki alternatif perpindahan dan penenempatan barang untuk mengatur volume barang masuk.

\section{B. Saran}

Untuk mendapatkan hasil yang selalu update pada tiap kasus yang berbeda, setiap kali mendapatkan contoh umpan balik dilapangan maka diberikan saran sebagai berikut :

1. Dapatkan informasi volume barang masuk terlebih dahulu agar operator dapat membuat estimasi dan mempertimbangkan alokasi area penyimpanan barang antar departemen.

2. Mengevaluasi layout dengan menghitung pergerakan komposit antar departemen dan memeringkatkan dari kebanyakan gerakan ke gerakan paling sedikit.

3. Untuk memungkinkan konvergensi cepat ke solusi optimal, perusahan dapat melakukan gabungan teknik algorima The MASS (Modified Assignment) bila terdapat pengelolaan gudang dengan kapasitas lebih besar.

\section{DAFTAR PUSTAKA}

M. Hudori. Impelementasi Penyusunan Barang di Gudang Finished Goods dengan Metode Class Based Storage. 16 Maret 2018. 
http://www.academia.edu/30458842/lmple mentasi_Penysunan_Barang_di_Gudang_ Finished_Goods_dengan_Metode_Class_ Based_Storage

M. Khoshnevisan, Dr. 2003. Optimal Plant Layout Design for Process-focused Systems. $16 \quad$ Maret 2018. http://www.me.utexas.edu (http://www.me. utexas.edu/ jensen/ORMM/omie/computati on/unit/lay_add/lay_add.html)

Moh.Nazir. (1998). Metode Penelitian. Jakarta : Ghalia Indonesia.

Mulcahy, David E. 1994. Warehouse and Distribution Operation Handbook. International Edition. McGraw Hill. New York. Yogyakarta: Graha llmu.

Santoso, Helina, Febianti. Usulan Tata Letak Gudang Produk Jadi Metode Shared Storage dan Pendekatan Simulasi di PT. Lotte Chemical Titan Nusantara. 15 Februari 2018. https://jurnal.untirta.ac.id/index.php/jti/articl e/viewFile/1408/1119

Sugiyono. 2008. Metode Penelitian Kuantitatif Kualitatif dan R\&D Bandung : ALFABETA

Wignjosoebroto, S. 2003. Tata Letak Pabrik dan Pemindahan Bahan. Surabaya : Guna Widya.

Wignjosoebroto Sritomo, 2003, Tata Letak Gudang dan Pemindahan Bahan. Surabaya : Guna Widya.

Zhenyuan, Jia, Lu Xiaohong, Wang Wei, Jia Defeng, Wang Lijun.2011. Design and Implementation of Lean Facility Layout System Production Line. International Jurnal of Industrial Engineering. Vol 18(5). hal 260-269 